\title{
Musings about Metaphors and Models: the Need to Put Psychology Together Again
}

\section{Nandita Chaudhary ${ }^{1} \cdot$ Sujata Sriram ${ }^{2}$}

Published online: 26 August 2020

(C) Springer Science+Business Media, LLC, part of Springer Nature 2020

\begin{abstract}
Zagaria, Andò \& Zennaro (2020) raise several issues for the study of the human condition, highlighting the precarious status of psychology on account of a core weakness: The absence of consensus about fundamental concepts. Using the metaphor of a giant, albeit one with feet of clay, the authors develop an argument about how evolutionary psychology is the best possible candidate to advance a unified paradigm on account of theoretical consistency. In this commentary we examine the metaphors and models invoked in the article and suggest alternative perspectives on the grounds that a grand singular solution and consistency in definitions are not urgent requirements for understanding the complexity, diversity, and nuances of the human condition. We argue that plurality and low consensus can be taken as productive and functional; precisely because psychological and cultural phenomena are always characterized by uncertainty in irreversible time. Cultural psychology is a valuable paradigm, inclusive of universal and individual processes in ways that provide more appropriate resolution for cultural pluralism. Every definition of psychological phenomena, however obscure and contested, has arisen from theoretical speculation arising from a specific perspective.
\end{abstract}

Keywords Psychology $\cdot$ Evolutionary psychology $\cdot$ Cultural psychology $\cdot$ Metaphors

Nandita Chaudhary

Nandita.chaudhary@gmail.com

Sujata Sriram

sujatasriram@gmail.com; sujatas@tiss.edu

1 University of Delhi, New Delhi, India

2 Tata Institute of Social Sciences, Mumbai, Maharashtra, India 


\section{Fragmented Structures, Fragile Branches and Decontextualized Methods}

Psychology is the scientific exploration of human thought and behaviour. The configuration of these domains can be remarkably dissimilar in different traditions, although they are guided by similar preoccupations to understanding the human condition. The objects of interest for psychologists are historically, socially and linguistically constructed and can be vastly divergent based on problems, assumptions and taxonomy, which, Danziger argues, are not "exempt from the flux of history" (Danziger 1997, p. 12). In terms of categories, we agree with the authors that there may be little consensus on foundational concepts like mind, cognition, emotions, intelligence and others, but it is important to remember that unlike the natural sciences where concepts have precise meaning, psychological constructs are 'field-like signs' (Valsiner 2007). "Field-like signs are generalizations that allow for heterogeneity within the field......All open systems are characterized by equifinality which requires the acceptance of heterogeneity at the abstract level" (Valsiner and Salvatore 2012, p. 15). Point-like signs, where meanings are specific, clear and defined, cannot represent the multilinearity that open systems require. The affect-laden, fuzzy quality of psychological constructs renders them a field-like quality, where a range of related but somewhat different sense can proliferate. Turning these into a point-like concepts transforms the very nature of meaning-making, a process that is a negotiated understanding between individual understanding and social representation (Valsiner 2008). Psychology's main subject on etymological grounds is the fuzzy concept of the 'soul', an association that has been dismissed as an irrelevant historical detail. The field-like nature of concepts in psychology makes any simple comparisons with the pure sciences difficult. Such a task can be accomplished by looking at continuities in the project of advancing science in any field using a holistic perspective rather than a reductionist one.

Fragmented Domains There is an urgent need for psychology to be put back together like the shattered Humpty Dumpty (Hampden-Turner 1971, p. 11). The separation of different domains like affect, cognition, learning, sensation, and perception have become scattered across numerous books and journals, and a consolidated view of a person is hard to find. Furthermore, hyphenated expressions like psycho-somatic, psychobiological have added to this disconnect (Laing 1965). This is especially in practical applications like therapy where these fractures result in obscuring the access to and addressing of the difficulties faced by individuals. The tripartite division of physical, cognitive and emotional is another instance of fractures created by the separation of specialization that have real-life consequences on children's learning. For instance, policy related to school participation among children in many countries, focuses too much on cognitive and language domains at the expense of other areas of development (Cohen 2006). Specialization and fragmentation have had significant practical consequences. Separations between body and mind, nature and nurture, physiological and mental are other examples of fragmentations that have hindered the understanding of both the body and the mind (Van der Kolk 2000), domains became fields in themselves and dedicated journals rarely address common concerns. As the domains and distributions became smaller and more distant, the conceptualization of the whole individual and connections with context were obscured. Thus in addition to a splintered image of the person, another important consequence was the separation of person from context. 
These domains that we have been treating as essential features of the human condition are conventions, emerging from a specific tradition of psychological study, and far from universal (Danziger 1997). In fact, the reification of these constructs has created an illusion of their existence as identifiable features. As Cole (1996) remarks about the invisibility of one's own culture as a way of life, perhaps psychologists too were blind to their own cultural roots. This was primarily because of the obsession to be seen as a science. A similar intent is evident in Zagaria et al. in their desire to develop a paradigm using evolutionary psychology.

Fragile Branches The issue of specialization and compartmentalization between subdisciplines in Psychology is a case in point. Has the creation of so many different branches led to fragmentation in the study of the human mind, where little pockets of specific perspectives in fact add to the problem rather than solving it? This happens in all fields of study, as the discipline grows, specialization is inevitable.

In this sense, the labels used for many of the sub-disciplines of psychology can be argued as tautological. For instance, if development is a basic feature of psychological processes, why is there a need to separate developmental psychology as a specific area of study? Furthermore, what is labelled as developmental psychology, the study of agedifferences and normative behaviour, are in fact, not even developmental in the true sense because they derive from simple comparisons with cross-sectional samples, whereas development is an open-ended, dialectic process in time (Shanahan et al. 1997; Valsiner 1997). Notwithstanding this misrepresentation, development is a basic aspect of mental processes in fact of all life forms. Similar arguments can be made about cultural psychology, or evolutionary psychology for that matter. If development, culture, or phylogenetic processes are examples of basic psychological processes, why are these added as adjectives? Have these numerous branches simply allowed the proliferation of specialization to the extent that it has become counterproductive for a consolidated view of an individual? This sounds a bit like the Humpty Dumpty story except that in this instance, the pieces are also often at war with each other about who is more important than the other!

In Jörg's work on complexity in the social sciences (Jörg 2011), consolidation is being called for. Rather than breaking down disciplines, the author calls for a "New thinking on complexity for the Humanities and Social Sciences" focusing on the complexity of realworld complexity as a new science. It is the dis-satisfaction with the social sciences in the handling of complex human phenomena which provides the push for a complementary, consolidated science born out of a crisis, a crisis from the outcomes of the "common trivialization of complex phenomena" especially in the fields of learning, education and brain research where scientists have become imprisoned by descriptions (p. 1, 2). There is a call for revising concepts like causality and interaction, focusing more on a generative approach for a general, transdisciplinary science that is better able to handle unexpected and uncertain aspects of human social and psychological phenomena. This is an attempt to reverse the direction of scientific study from fragmentation to integration, utilizing the shift from fission to fusion in theory construction.

Methodological 'Purity' and an Indifference to Context Driven by the inspiration to emulate the physical sciences (physics in particular) and a complementary discomfort with context, psychological investigations have tended to favour laboratory experiments, structured observations, and measurement. Research in the quantitative tradition is placed 
at a higher status, and although it may have been initially proposed as "the Second Psychology" by the founders of the subject (Wundt in particular), other methods became subordinated. Wundt's recommendations for experimentation were adopted, but selfexamination and introspection were ignored along the journey from Europe to America, as was his extensive work on Völkerpsychologie, or Folk Psychology, regarding human beings' participation in culture and Genetic Ganzheitspsychologie following the principle of 'the whole is more or different than the sum of its parts' (See Diriwächter 2008; Valsiner 2008). Lessons that contemporary psychology can benefit from within its own historical roots for presenting a unified theory.

Although the qualitative tradition from other fields and mixed methods have gained in significance, the superiority of quantification and 'objectivity' remains undefeated. This has had many consequences on the content of psychological research and its 'weirdness' (Chaudhary and Sriram 2020). The conditions demanded of standardized techniques are often far too expensive and inconvenient to be replicated in other countries, even if the tasks may be fully applicable which is mostly not the case (Chaudhary 2008). Thus, the bulk of research retains its 'purity' by undermining other forms of enquiry, thereby perpetuating the myth of measurability of psychological phenomena and their independence of context (Kagan 2012). Valsiner (2014) has argued extensively about the need to bring data and phenomena closer together in order to better grasp psychological reality.

The Embryonic Fallacy, Intersubjectivity and Interobjectivity The myth of the independent individual is a strong feature of Psychology, resulting in a preference for intramental phenomena at the cost of social processes. The greater attention to issues of individual, inside-the-head events has had important consequences. This is related to the assumption that whatever transpires in a human life is an outcome of a single lifetime, and has little to do with social circumstances and cultural setting. Moghaddam (2010) writes that this is a major blind-spot in psychological theorizing, identifying the embryonic fallacy as the (false) assumption that everything that happens to us as individuals is the consequence of a single individual's lifetime. This approach tends to mute inter-subjectivity, the relationships between people and its co-dependence upon inter-objectivity, or the ways in which social relationships are structured by collective culture. Another significant and related issue is the phenomenon of treating all human conduct as emerging from thought. Some related problems that require attention are discussed.

Psychologization and Biologization Psychologism literally means 'to make something psychological', and psychologization implies the transformation of social, political or moral issues into psychological factors like well-being or self-processes, whether this is done deliberately or otherwise. The accelerated growth of Psychology in the twentieth Century is an outcome (Madsen and Brinkmann 2010) that has captured our imagination and sustained specific forms of psychological theory and practice, within which powerful myths about the human condition have been proposed. We remain seduced by our own sense of self-importance and must heed the warning to seriously consider alternative versions.

Burman (1994/2017) argues that psychologization is an obstinate problem despite the many changes in the world order in recent decades. Although global relations, 
immigration and environmental crises have heightened, and neoliberalism has impacted how we understand childhood in the contemporary, technologically connected world, we persist in attributing performance and participation of individuals and groups primarily to psychological factors, and everyone lands up becoming a psychologist (De Vos 2008).

Another important phenomenon is the biologization of conduct, and the renewed importance of the neurosciences in explaining behavioural outcomes. Madsen and Brinkmann (2010) argue that attributions to neural activity has in fact thrived on the foundation laid by psychologization, that origins of our world lay in the understanding of the mind as separated from and superior to the rest of the body as well as social reality. Bruer (2001) argues that "the purported new breakthroughs were in fact 'old' neuroscience. These results were carefully selected, oversimplified, and overgeneralized and then woven into arguments that were quickly lapped up by science journalism. Neuroscience and the brain have a strong hold on the popular imagination. Once claims that the first three years of life were critical for brain development appeared on the covers of Newsweek and Time magazines, upper middle-class parents world-wide became students of the new brain science and consumers of brain-based products. Regardless, the trend has persisted. In fact, the use of the neurosciences argument can be explained as a sort of hyper-generalization in the theatre of research (Valsiner 2019), a sort of exaggerated posturing to impress consumers, influence policy and silence dissent. The strategy has been widely successful. The notion of neuroliberalism is invoked here as the rise of the use of research in the behavioural sciences in governance and assumptions of economic progress under neo-liberalism. Children's minds become positioned as baby brains and our worlds are captured by ideas of personal progress as a consequence. With the entry of behavioural economics there has been a further escalation of the use of research in the drafting of public policy world-wide (De Vos 2016).

These ideas need to be strengthened and supported, since it appears that forces within the discipline, like the enhanced reliance on the neurosciences and evolutionary biology seem to have taken the place of animal studies in the past. The problem with these trends is that once biology and physiology are given a primary position, the question arises of "why should we worry about childhood environments in the nonWestern world?" (LeVine 2017, p. 29). We need to be concerned because most of the world's people live in such environments, and what happens to them should be a matter of central concern to psychology.

\section{Is Psychology a Science?}

In 2012, an article in the LA Times titled 'Why Psychology Isn't a Science', by Alex Berezow (2012) raised eyebrows.. Writing about psychologists claim to be viewed as scientists, Berezow used Happiness research to make his claim. He argued that psychology did not fulfill five basic criteria of being a science: terminology, quantifiability, highly controlled experimental conditions, reproducibility and, finally, predictability and testability. This led to a huge reaction from the scientific community, for and against the position. Around this time, several reports related to false claims in psychological research were unearthed, leading to further turbulence (Callaway 2011), and more importantly, well-known claims in social psychology came under suspicion 
for exaggerated and even false claims. Most recently, a giant of twentieth century psychology, Hans Eysenck, was knocked off the pedestal (O'Grady 2020). The question we raise here is not whether psychology is a science or not, but why the special status of the social and human sciences has not been adequately articulated. After all, the study of human phenomena places several constraints and affordances which cannot be ignored. Uncertainty, subjectivity, irreversibility, irreducibility, context-dependence, self-reflexivity and purpose are important features of the human social sciences, placing very specific demands on theory and method, as well as constraining the ways in which experimentation can be done.

The human mind is so complex and versatile, that many aspects of its functioning can only be estimated. The "principle of original multiplicity" (Shweder 1996, p. 41) proposes that many facets of mental functioning can only become activated when there is an encounter with something else, a multiplicity that is a shared feature of being human. This is the reason why we are even able to communicate with each other across biological, linguistic, cultural, and ethnic boundaries, making diversity the universal feature of being human. As Arendt wrote so eloquently "If people were not different, they would have nothing to say to eachother. And if they were not the same, they would not understand each other" (Arendt 1958, p. 155).

The Need for Comparisons Although one can understand that definitions in physics and chemistry are more accurate and quantifiable than definitions of happiness or attachment, it is important to understand that not everything can be represented by numbers to the decimal point. The usefulness of psychological research is not because of quantifiability; but results that reveal something about human nature that can be understood universally, even when the experience is local. One can also argue that social scientists tread on slippery ground when they try to express phenomena too accurately. Psychology has to deal with contextual relevance as well as uncertainty, but that does not mean, that it is useless.

But the claim that science is restricted to empirical data is false. To claim that the hard sciences always rest on observable fact is a misrepresentation. The fact that everything cannot be precisely defined and not always measured is not a failing of psychological research and method, this is a feature of the phenomenon, and acting otherwise will be erroneous.

\section{Evolutionary Psychology: Theory and Applications}

In this section we examine the theoretical, methodological and practical explanations that evolutionary theory has proposed. Evolutionary psychology (EP) has tried to provide a unifying perspective by using psychological mechanisms as explanations for mind and behaviour. EP focuses on the study of traits, believed to be the functional products of natural selection, and the principles are applied to psychological traits like brain functioning and other internal psychological mechanisms that persist because of survival and reproduction. Behaviour is mostly explained through biological processes of adaptation, as algorithms for survival.

The attempts to treat EP as a unifying and universal explanation for all behaviour has received much resistance, especially where reduction to biology cannot fully explain 
behaviour. These and other problems with the approach are clearly outlined by Zagaria et al. as well as delineating the fact that some evolutionary psychologists tend to give importance to environmental influences while believing in the framework of EP. The need is to focus on the core ideas that "our mind and behaviour are significantly shaped by our phylogenetic history" (Zagaria et al., 2020, p. 15). Our social nature and the social nature of the brain are its distinguishing features that make us unique and the social environment has a "selective pressure to shape our psychological functioning" (Dunbar 2009), and our social competence is permitted by our biological functioning. In other words we are cultural because our biology permits it, an assumption that would be incredibly hard to substantiate. In this manner, EP addresses the innateness, universality, as well as the social nature of human beings, since we are biologically predisposed to responding to the environment, each human being becomes unique, making it the most complete and multifaceted approach to understand human psychological functioning (Zagaria et al., 2020, p. 16).

In simple words, the human mind is seen as a system governed by natural selection to acquire information from the environment, and unravelling behaviour requires the understanding of these underlying dynamics that are claimed as adaptations that helped people to survive and reproduce. The cognitive programs of the human brain may not be adaptive now; they were adaptive in ancestral environments. The focus is clearly on intramental processes. What is important to note about the research is that all behavior is assumed to be explained in terms of underlying psychological mechanisms that are adaptive and original.

Some important gaps in evolutionary theory have been identified in examining the principles on which the theory is based. Firstly, the claim that context is only relevant for the earliest humans in their adaptation to environmental challenges fails to find acceptance. Can context, environment and history be disregarded to the extent that evolutionary psychologists attempt? While evolution cannot be denied, or disregarded, attempting to make gross generalizations fail to capture the nuances of behavior that exist, and which develop in response to the context. While the mantra of Cosmides and Tooby (1997, pg. 90) "Our modern skulls house a stone age mind" may be very catchy, it fails to capture the essence of all the changes that have taken place from the Pleistocene age. The role of culture and history in human behavior are ignored.

On account of the fact that EP fails to conform to the 'rigorous standards' of both biology and psychology, and is also unable to explain the relation between genes and the context, the theory fails to provide an complete understanding of evolution of behavior (Nash 2014). The only context that is considered relevant is the environment of the early ancestors or EEA, conditions that we can only speculate about. Assuming that present day behavior is a reflection of adaptation gives little evidence about the reasons for the occurrence of the behaviors and how they may have changed over time. With emphasis placed on the evolutionary past, the focus is shifted away from contemporary issues, norms, values, and physical aspects that influence behavior.

In explaining language from grunting to systems of complex communication, EP argues that language acquisition abilities have evolved and advanced through the process of natural selection and one could understand how advanced language skills can contribute to a person's safety, survival, and reproduction. Nevertheless, the language or languages we learn depends on the language spoken in our homes and 
neighborhoods, demonstrating the importance of cultural input and context. It is the dimension of nurture that evolutionary explanations seem unwilling to embrace.

Furthermore, the methods used by researchers and the practical applications of the theory have been criticized for the inability to explain many aspects of human behaviour. Trying to understand all behavior using biological bases is simplistic and artificial. For qualitative researchers, the critique about evolutionary psychology stems from the methods used. "Evolutionary psychology uses all of the standard methods of investigation available to psychologists to test hypotheses, including laboratory experiments, observational techniques, questionnaires, physiological techniques, mechanical recording devices, genetic methods, and brain imaging techniques" (Confer et al. 2010; pg. 112). These methods go against the grain of qualitative researchers (Jonason and Schmitt 2016), where the focus is more on understanding the why of phenomena, rather than just seeing that they exist. EP methods are reductionist and ahistorical in nature, which may account for some of the opposition from qualitative researchers, feminists and people of non-normative sexuality. According to Smith (2020), the claim that psychological causes of contemporary behaviours are "Strong vertical homologs of the corresponding adaptations" in the EEA are claims that are simply unjustifiable (p. 48). There are no methods available that could provide evidence to explain these claims.

EP fails to explain homosexuality and homosexual orientation (Confer et al. 2010; Jonason and Schmitt 2016). This is possibly the reason why academics of homosexual orientation are likely to be critical about the principles of evolutionary psychology. Speaking at length about the practical applications of evolutionary psychology in areas like clinical work, Confer et al. (2010); the use of evolution-based treatment for depression while of interest, is simplistic. Can the similar explanations be extended to other pathological conditions like suicidal tendencies? While evolutionary principles can be used to explain phobias, extending from there to treatment of the same is difficult.

Another group of academics who extend a serious criticism to evolutionary explanations are feminist psychologists who endorse nurture explanations over biological explanations since the understanding of a social construction of gender would not accommodate the postulates of EP (Cowan 2014). Additionally, feminism espouses a political cause, while according to Buss and Schmitt (2011), EP does not have a political agenda. The point about the political agenda of EP has been challenged by feminists, who claim that the latter are sexist and racist, seeking to preserve the status quo of existing power structures in society (Grossi et al. 2014). EP claims to use dispassionate science, and any refutation of such science has been seen by the likes of Steven Pinker to be the modern day equivalent of burning witches at the stake.

Human cultural traditions have actively shaped our context and the interaction of evolutionary forces with cultural context results in differences in the human population. Much of the discussion in EP on mate selection and partner choice, attributes the same to physiological and genetic changes as a result of the environment. Such explanations for sex and mating behavior have been challenged by Parameswaran (2014) who explains why the evolutionary explanations of mate selection do not adequately account for the role played by history and culture. The role of European conquest on mate selection and marriage practices in large parts of the world probably account for the apparent similarities. Prior to colonization the diversity existing in child-rearing and 
partner choice was immense, as seen from historical records. The arrival of the JudeoChristian ethic and values resulted in transformation of practice, seen as offensive for the colonizers. The transformation of matriarchal communities and exchange of collectivistic values by more individualistic ones are all part of the same process of colonization. EP takes an ahistorical view of psychology, resulting in disembodied explanations of behavior. Context does not figure in most of the explanations provided by EP, which is problematic.

A Force Fit Many of the problems besetting psychology at present, which have necessitated the paper by Zagaria et al., have emerged because of the desire to consider psychology as a 'hard' science. We see the adopting an EP paradigm as a force fit. Taking the example of the response to the recent coronavirus pandemic, emerging observations have led to the constant need to modify and adapt the claims based on context. A context free, ahistorical, a-material psychological paradigm goes against the grain of the subject matter of much of psychology - people. If we see psychology as a 'soft', rather than as a 'hard' science, there will be fuzziness - which gives rise to the 'it depends' aspects. The fact that psychological phenomena are defined by situation and culture, indicates the extent to which we are all as human beings affected by context, culture, and history, all of which are denied by EP. Not having clear terminology does not make psychology a pseudoscience. Lack of clear terminology can be seen in disciplines such as chemistry, which are never considered as non-science. Psychology does provide useful answers to questions, and while it can be used more to explain behavior, going the route of EP does not serve the purpose.

Just as physical and social sciences work together on interdisciplinary studies and projects to understand and come up with solutions that afflict human beings, the different branches of psychology need to work together, rather than pulling in different directions. Furthermore, given the way language functions, there will never be one definition of psychological terms and concepts. If we find that there is an inconsistency in definitions within the English language, one can imagine how much more confounding it would be to translate meaning into other languages which may or may not have an equivalent word. Case in point, intelligence - how can intelligence be translated into Indian languages? The word in Hindi for intelligence (buddhi) is the same as the word used for wit, sagacity and wisdom, whose prime features are discrimination, decisionmaking, immediacy, freshness, clarity, and transcendence. The social dimensions of effective interpersonal wisdom, emotional competence and entrepreneurial skill are additional aspects of intelligence that are regarded as components of such a quality as intelligence in the Indian context (Srivastava and Misra 2007), a perspective that is quite divergent from the English meaning.

Scrambling for Universals The search for psychological universals as attempted by Zagaria et al. is not new. However, the problem is how to identify these universals, and to consider why having these universals is important. Norenzayan and Heine (2005) examine the fields of evolutionary psychology and cultural psychology while developing a methodological and a conceptual framework for understanding psychological universals. Identifying universals across cultures can be extremely important in designing interventions for cultural and social problems across the world. Dealing with child abuse, or examining the effects of poverty, or developing 
universal rights for children requires universal understanding of concepts of child/ children, poverty, rights, and abuse. It is here that problems arise. It is impossible to have a universal definition of any of these concepts. The framework of universal rights of children have been developed from western notions of what is right for children and exclude children from most parts of the developing world from apprenticeship options. Again, who decides what is universal?

Attempts at unification in psychology are not simply for the purpose of consensus. The main reason is to develop a theoretical synthesis about features that characterize human mental phenomena. As Valsiner (2008) argue, science develops through processes of abstracting generalisation, "Starting from the phenomena, and inductively derived first knowledge, science proceeds beyond the common sense (and common language) to arrive at axiomatic general views, from which (deductively) a theoretical framework is created" (p. 214), simultaneously focussing on the whole and constituent parts.

In the Western tradition, explanations of human behaviour until the early twentieth century were bound by the assumption of biological differences between races. It was the scholarship of Franz Boas who replaced race with culture, a set of learned behaviours, towards cultural determinism. The legacy of Boas, Ruth Benedict and Margaret Mead argued that if culture was learned, then it could also be improved, people were no longer bound to the biological inheritance and but they were also released from cultural determinism because culture itself could be shaped. The possibility of understanding human behaviour became released from biology as well as culture, since cultural institutions were not perfect and foundations of society are not permanent since there is imperfect replication from one generation to another (Dresser 2020).

For the human sciences in general and psychology in particular, context is constitutive. The person and environment are in constant dialogue and any attempt to separate these processes is artificial and unrealistic. Phenomena are subjective, ephemeral and even elusive, making access a constant challenge. Sensitivity to context, time and person adds to the complexity of investigating phenomena that makes the template of the natural sciences, physics in particular, an inappropriate model for Psychology. This emphasis on observations, measurement and objectivity resulted in significant gaps in the enterprise of understanding psychological phenomena. Parallel with heightened compartmentalization, theories developed from culturally specific formulations of the psyche and limited contexts were adopted as universal principles, guidelines and norms for behavior and development. Psychology has been fragmented and incomplete, and also erroneous. The discomfort with 'culture' has resulted in the systematic disregard of context and the treatment of real-life circumstances as 'noise' or distraction. In this tradition, the laboratory is promoted as a 'pure setting', but for us contextdependent and complex humans, the lab is an environment, with its unique features that impinge upon behavioural outcomes.

History is written by victors, and this is true also of mainstream Psychology, although there are significant challenges to the dominant position promoted in journal articles (Kagan 2012). Culture became understood as a feature that could be manipulated, rather than an inexorable reality. In Psychology, the ripples of the cultural revolution was felt, but did little to destabilise the experimental method. 


\section{Psychology's Purpose}

The primary objectives of Psychology are to describe, understand, explain and predict the human condition and to consolidate findings from research to expand and refine our theoretical understanding of human thought and action. In fulfilling these tasks, Psychology has accomplished a great deal, but often remains incapable of handling complexity, diversity and uncertainty that characterizes its subjects. We now know a lot more about the functioning of developing minds and activities, how people think about the world around them, their social relationships, and their emotions. Yet, the data base from which these findings have been gathered constitute a relatively small number of people and there has been a failure to adequately represent diversity, both by reducing the study of contexts (Kagan 2012), conceptual and practical disputes (Burman 1994/ 2017) and samples used for research (Henrich et al. 2010). A thorough examination of research studies over the years demonstrates a WEIRD bias in sampling (Western, Educated, Industrialized, Rich and Democratic societies), mostly limited to accessible groups like university students. Despite intense criticisms and extensive debate, there remains a persistent sampling bias in developmental research based on methodological and theoretical preferences (Nielsen et al. 2017). Psychologists may have to perforce accept the inability to generalize from these samples or be compelled to expand the sampling base. The latter is more difficult.

Through reverse construction from University curricula, research topics, contents of books, we realize, as Zagaria et al. demonstrate so effectively, that psychology is a "giant with feet of clay" where there is little consensus about the basic building blocks of the discipline. Let us add to this weakness by looking at another dimension that becomes substantial when we look at the public awareness about the subject. In public imagination, Psychology is understood as a body of work based largely on theories and experimentation related to self-knowledge, intimate relations, well-being and therapy, findings from which can be quickly applied to turn educational settings, personal perspectives or group relations towards more beneficial outcomes. Business management and organizational behavior are applied fields of psychology, which pay lip service to the parent discipline, and the principles are supposed to be applicable from the west to the rest.

A quick look at public libraries or bookstores will provide an easy access to this understanding. In the transfer of knowledge, there is little energy spent on where the research emerges from, under what circumstances and what will be the outcomes of such alterations to the larger systems in operation. A plethora of self-help and selfdevelopment manuals and books are available, all implying that there is a need and scope for improvement, for betterment, and we can all aspire for that goal. And these are things which are culture blind-applicable for all people. And the same manuals are translated from English into other languages as well.

Yet, even in academic circles, higher education and research laboratories, these domains are popular. Such transfer of knowledge arising from experiments in learning, understanding, behavioural choices or moral standards eschews the complexity that Jörg (2011) raises. In this sense, Psychology has failed to address world-wide concerns, and remains driven by a relatively narrow range of assumptions about human behaviour. Psychology has primarily focused on the individual. The application of psychological principles to social and group behavior is not as widely used as compared to the 
individual factors, especially when we look at abnormal psychology. This has been the ace in the hand for psychologists, the fact that we can explain and treat abnormal behavior, in the interests of the group and society as a whole. The DSM pays lip service to culture, by recognizing that there are culture specific disorders that need to be studied (Stein et al. 2010).

\section{Musings about Models and Metaphors: A Giant with Ten Heads}

In a recent conversation, $\mathrm{I}^{1}$ was queried about what Psychology has to say about the probable consequences of conflict with the father on a person (the sex of the person was not specified). My reluctance to be trapped in a long conversation was overthrown by the desire to take on the challenge since that is exactly what it was! The question was thrown at me by an Engineer by training, who had this underlying skepticism of the 'softer sciences' that ranged between denial and disbelief. Psychologists are often confronted with such tricky questions that emerge from the desire to provoke rather than prove anything. It is often for the purpose of 'exposing' the assumed failure of psychology to explain anything, because one often lands up answering truthfully that "It depends". Something in the tone of voice was irksome enough for me to launch into a long-drawn explanation of possibilities regarding the sex of the child, nature of the conflict, its frequency, intensity, and duration, the age of the child at the time of the conflict, other people in the family and so on. One thing is for sure, I said, the persons emerging from a conflict-ridden situation were unlikely to remain neutral to the issue. At the end of it, I arrived at a final conclusion "So, it depends". Yet this time, the concluding answer was, in fact, far more thought out and explained than a foreclosure of "It depends", which can be construed as: "So you really don't know".

We use this illustration to highlight the fact that in the public imagination, psychology fails to stand up to the demand to provide answers, simple ones. But as Jörg points out, just because simple answers appear scientific because of the linearity and avoidance of uncertainty, they cannot represent the complexity of human dynamics. Social and human sciences deal with people, groups, and communities which are complex systems. This way, the long answer to reach "it depends" is, in fact, a more accurate approximation of the truth, as far as we know. Just because the phenomenon is complex, does not mean that science cannot explain what possibilities can emerge and why. The short answer "It depends" is thus very different from the long answer "It depends", the two words are the same, but the journey of uncertainty and possibilities does not make it impossible to explain (short answer). The second, the longer answer, acknowledges the fundamental complexity of human nature and its circumstances.

Attempting to replace the giant with feet of clay, we offer an alternative, an Eastern metaphor, deriving from the divine figure in the Hindu epic, the Ramayana. Ravana is a scholarly deity, considered evil and divine, depending on which side of the Gulf of Mannar you write from. In Sri Lanka, Ravana is worshiped as a great king, while most of Hindu India considers him as evil (Bains 2017). Ironically, the worship of Ravana still happens in many parts of India since Hinduism does not preclude the possibility of constructing divinity with a dark side and demons with divine traits. In Kakinada, Andhra Pradesh there is a Shivalinga supposedly installed by Ravana himself, and both

\footnotetext{
$\overline{{ }^{1} \text { Nandita Chaudhary (first author) }}$
} 
are worshipped. There are temples dedicated to Ravana in other parts of India as well. Ravana was a great Shiva devotee, and the name meaning the one who roars loud, was bestowed on him by Lord Shiva himself. The mythology of Ravana is nuanced and multilayered. While popular culture in India shows Ravana and his brother Kumbhakarna as wicked, lustful, cruel demons, the narrative in the ancient texts of the Bhagavata Purana and Ramacharitamanasa present an elaborate back story. Both brothers were attendants of the god Vishnu, cursed to go through three rebirths where they would be in conflict with the god. According to legend, Ravana would be killed by a human, in the form of Rama, as shown in the epic Ramayana.

According to one version of the Ramayana, Ravana's multiple heads was an optical illusion, from the nine pearls gifted to him by his mother at birth. In Hindu mythology, having multiple heads is symbolic of the powers of the deity. In Ravana's case, the ten heads represent the capabilities and achievements he acquired. There is complete consensus about the fact that Ravana was a scholar, a statesman, a great musician and a physician. The ten heads represent his mastery over the four Vedas and six shastras (Hindu treatises). This savant brought about his own downfall through his lust for Sita, eloquently depicted in the Ramayana.

We offer Ravana's ten heads and multi-faceted personality as an alternative metaphor for Psychology, a giant with many powers, but one that can also be deeply misunderstood and misrepresented (Picture 1).

\section{The Entry of Culture}

While the article by Zagaria et al. examines how concepts commonly used in psychology are inadequately defined and explained in basic textbooks, there are other

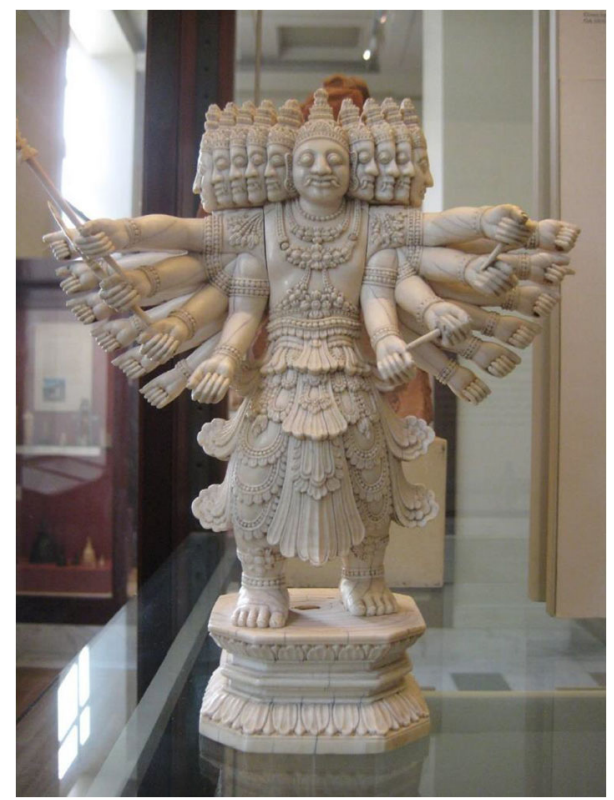

Picture 1 The ten-headed Ravana Source: The British Museum, https://en.wikipedia. org/wiki/Ravana\#/media/File:Ravana_British_Museum.jpg 
dimensions that need to be considered, which expose the feet of clay. Some of the most popular experiments in social psychology, the compliance studies by Milgram, the prison experiments by Zimbardo, would, in today's academic climate, be shot down by ethics committees. Similar controversies came up in Anthropology when Freeman questioned Mead's work on sexual mores of Samoans. Maybe that was the aim - have problematic experiments that would task academia to question their stance, their ethics, and their politics. While on the one hand psychologists tread the high moral ground, and refuse to be drawn in to comment on or critique policies, psychologists have conspired to work with governmental agencies against people who are seen as being critical of the establishment. In countries like India, psychology is a marginalized field with little respect from the sciences, who regard it as a pseudo-science, or a soft science, while the humanities regard psychology with skepticism, as a field which focuses on individuals, rather than being able to command a more discerning view of the world, people and problems. Psychology in countries like India is a subject for urban dwelling elite. Most writing in psychology is in English, which is not the language of the masses. Basic textbooks in psychology are rarely written by Indian authors for an Indian audience. Most often, translations are just that well-known books from publishers are translated with a few select examples to represent the cultural flavor.

\section{Concluding Comments: A Unifying Framework of Psychology}

In their concluding section Zagaria et al., (2020) argue that Evolutionary Psychology provides a framework that could help psychology advance from its pre-paradigmatic stage, but caution the audience that the theory is not to be taken as a "monolithic theory but as a comprehensive, conciliatory approach" (p. 17) for the purpose of coherence and consistency.

Based on the discussions, any approach to unify psychology cannot take place without attention to the basic properties of psychological phenomena. Consensus in itself cannot be an objective since it tends to ignore silenced voices and pluralistic vision. For a science of human behaviour, such an imposition can be hegemonic as we have learnt (Burman 1996). The possibility of minimal consensus that there is no disagreement, is an option.

The problem with using the unifying framework of evolutionary psychology is precisely the one articulated about 'cultural psychology' or 'developmental psychology', unlike other sub-disciplines that intend to separate domains of behaviour and thought, like organizational psychology. When we use labels that employ a key characteristic of being human as an adjective, the purpose is to focus on that feature. When key elements of human nature are used as adjectives, they tend to imply that there are areas of activity that are not social, cultural or developmental, and in this case, not evolutionary. We argue that the separation of sub-disciplines by recognized aspects of the core nature of psychological phenomena is misleading. We propose the following. Accepting the claims of social, developmental, cultural, evolutionary nature of human beings, the unifying framework should include all four. Alphabetically this would read: Cultural, developmental, evolutionary, social psychology. Or else, we could just call it Psychology because the separation is tautological. Ravana did, after all, have ten heads! 
The task of consolidation and unification needs to be strengthened and supported, since it appears that forces within the discipline, like the enhanced reliance on the neurosciences and evolutionary biology, create fractures in the holisitic understanding of the human condition. In a post-pandemic world that has provided a long pause in our daily pursuits we have an enhanced opportunity and renewed reason to review the depths and direction in which the world is moving and the ways in which science is being studied, taught and practiced. This holds true for public health, medicine, and the social and human sciences. Psychological phenomena by their very nature are developmental, cultural, biological and social, this does not mean we add each of these to separate ourselves from others. Perhaps it is time for us to consolidate our theory under the giant label psychology rather than continuing to separate these domains that give people the opportunity to build empires rather than scholarship. Titles, labels and categories are important, and we need to look again at how the processes of separation have worked. Attempts at unification need to recognize universalism without uniformity, where common developmental processes in irreversible time are seen as coconstitutive of culture. Diversity and plurality is what is universal about the human condition (Menon and Cassaniti 2017). The search for meaning and the intentional worlds we live in are central to the process of meaning-making. This is the axiom that binds us, as does biological changes, both phylogenetic and ontogenetic. Can we imagine psychology without meaning, context and culture? As Clifford Geertz recognized, such a human being would be an "unworkable monstrosity" Geertz 1973, p. 49).

Perhaps this is a time for consolidation and unification of psychology rather than its separation or favour towards one or other processes to find a frame that is inclusive of developmental, cultural and biological processes taking place in irreversible time and in self-reflexive ways. The study of higher-order psychological processes involving intentionality, purpose, novelty, resilience and adaptability in a constantly changing world rather than traits assumed to be stable like intelligence, attachment or learning styles can only be accomplished under a system that recognizes these features as fundamental and not marginal (Valsiner 2014). To be human is to be cultural, to be human is to be social, developmental and biological. Thus, cultural processes are the substance of psychology and not the agenda of any sub-discipline to be placed in the margins as if 'culture' does not touch the core of pure individual, mental, stable psychology!

\section{References}

Arendt, H. (1958). The human condition. Chicago, IL: Chicago University Press.

Bains, Grace (2017). "A Demon For Us But A Hero For Sri Lankans, The Fascinating Story Of Ravana, According To Lanka”. www.scoopwhoop.com.

Berezow, A, B. (2012). Why psychology isn't a science. Opinion. L. a. times, July 13, 2012, Retrieved from: https://www.latimes.com/opinion/la-xpm-2012-jul-13-la-ol-blowback-pscyhology-science-20120713story.html

Bruer, J. T. (2001). The myth of the first three years: A new understanding of early brain development and lifelong learning. New York: The Free Press.

Burman, E. (1994/2017). Deconstructing developmental psychology (3rd ed.). New York: Routledge.

Burman, E. (1996). Local, global or globalized? Child development and international child rights legislation. Childhood, 3(1), 45-66.

Buss, D. M., \& Schmitt, D. P. (2011). Evolutionary psychology and feminism. Sex Roles, 64(9-10), $768-787$. 
Callaway, E. (2011). Massive fraud uncovered in claims made by social psychologist. Scientific American. Retrieved from: https:/www.scientificamerican.com/article/massive-fraud-uncovered-in-work/

Chaudhary, N. (2008). Methods for a cultural science. In A. Anandalakshmy, N. Sharma, \& N. Chaudhary (Eds.), Constructing research methods: Insights from the field (pp. 29-52). New Delhi: Sage.

Chaudhary, N., \& Sriram, S. (2020). Psychology in the "backyards of the world": Experiences from India. Journal of Cross-Cultural Psychology., 51, 113-133. https://doi.org/10.1177/0022022119896652.

Cohen, J. (2006). Social. Emotional, ethical, and academic education: Creating a climate for learning, participation in democracy, and learning. Harvard educational review, 76(2), DOI: https://doi. org/10.17763/haer.76.2.j44854x1524644vn.

Cole, M. (1996). Cultural psychology: A once and future discipline. Cambridge, MA: Harvard University Press.

Confer, J. C., Easton, J. A., Fleischman, D. S., Goetz, C. D., Lewis, D. M. G., Perilloux, C., \& Buss, D. M. (2010). Evolutionary psychology: Questions, prospects, and limitations. American Psychologist, 65, 110126.

Cosmides, L., \& Tooby, J. (1997). The modular nature of human intelligence. In A. B. Scheibel \& J. W. Schopf (Eds.), The origin and evolution of intelligence (pp. 71-101). Sudbury, MA: Jones and Bartlett.

Cowan, L. K. (2014). Feminist perceptions of evolutionary psychology: An empirical study. Dissertation: Texas Woman's University.

Danziger, K. (1997). Naming the mind: How psychology found its language. New Delhi: Sage Publications Retrieved from http://kurtdanziger.com/Naming\%20the\%20Mind.pdf.

De Vos, J. (2008). From Panopticon to pan-psychologisation. International Journal of Zizek Studies, 2(1), 120. https://doi.org/10.1177/097133360902200105.

De Vos J. (2016). The metamorphoses of the brain - Neurologisation and its discontents. Palgrave Macmillan.

Diriwächter, R. (2008). Genetic Ganzheitspsychologie. In R. Diriwächter \& J. Valsiner (Eds.), Striving for the whole: Creating theoretical syntheses (pp. 21-45). New Brunswick, NJ: Transaction Publishers.

Dresser, S. (2020). The meaning of Margaret Mead. Aeon Magazine. Retrieved from: https://aeon. co/essays/how-margaret-mead-became-a-hate-figure-for-conservatives

Dunbar, R.I. (2009). The social brain hypothesis and its implications for social evolution. Annals of Human Biology, 36(5), 562-572.

Geertz, C. (1973). The interpretation of cultures: Selected essays (Vol. 5019). New York: Basic books.

Grossi, G., Kelly, S., Nash, A., \& Parameswaran, G. (2014). Challenging dangerous ideas: A multidisciplinary critique of evolutionary psychology. Dialectical Anthropology, 38(3), 281-285.

Hampden-Turner, C. (1971). Radical man: The process of psycho-social development. In Garden city. NY: Anchor books.

Henrich, J., Heine, S. J., \& Norenzayan, A. (2010). The weirdest people in the world. Behavioural and Brain Sciences, 33(2-3), 61-83. https://doi.org/10.1017/S0140525X0999152X.

Jonason, P. K., \& Schmitt, D. P. (2016). Quantifying common criticisms of evolutionary psychology. Evolutionary Psychological Science, 2, 177-188. https://doi.org/10.1007/s40806-016-0050-z.

Jörg, T. (2011). New thinking about complexity for the social sciences and humanities: A generative, transdisciplinary approach. Dordrecht, NL: Springer.

Kagan, J. (2012). Psychology's ghosts: The crisis in the profession and the way back. New Haven: Yale University Press.

Laing, R. D. (1965). The divided self: An existential study in sanity and madness. London: Penguin.

LeVine, R. A. (2017). Challenging developmental doctrines through cross-cultural research. In an introduction. In J. L. Cassaniti \& U. Menon (Eds.), Universalism without uniformity: Explorations in mind and culture. (2331). Chicago, IL: University of Chicago Press.

Madsen, O. J., \& Brinkmann, S. (2010). The disappearance of Psychologisation. Annual Review of Critical Psychology, 8, 179-199.

Menon, U., \& Cassaniti, J. L. (2017). Universalism without uniformity: An introduction. In J. L. Cassaniti \& U. Menon (Eds.), Universalism without uniformity: Explorations in mind and culture. (pp. 1-22). Chicago, IL: University of Chicago Press.

Moghaddam, F. (2010). Intersubjectivity, interobjectivity and the embryonic fallacy in developmental science. Culture and Psychology, 16(4), 465-475.

Nash, A. (2014). Are stone-age genes created out of whole cloth? Evaluating claims about the evolution of behavior. Dialectical Anthropology, 38(3), 305-332.

Nielsen, M., Haun, D., Kärtner, J., \& Legere, C. H. (2017). The persistent sampling bias in developmental psychology: A call to action. Journal of Experimental Child Psychology, 162, 31-38. https://doi. org/10.1016/j.jecp.2017.04.017. 
Norenzayan, A., \& Heine, S. J. (2005). Psychological universals: What are they and how can we know? Psychological Bulletin., 131(5), 763-784. https://doi.org/10.1037/0033-2909.131.5.763.

O'Grady, C. (2020). Famous psychologist faces posthumous reckoning. Science, 369(6501), 233-234. https://doi.org/10.1126/science.369.6501.233 https://science.sciencemag.org/content/369/6501/233.

Parameswaran, G. (2014). Are evolutionary psychology assumptions about sex and mating behaviors valid? A historical and cross-cultural exploration. Dialectical Anthropology, 38(3), 353-373.

Shanahan, M. J., Valsiner, J., \& Gottlieb, G. (1997). Developmental concepts across disciplines. In J. Tudge, M. J. Shanahan, \& J. Valsiner (Eds.), Comparisons in human development: Understanding time and context (pp. 34-71). New York, NY: Cambridge University Press.

Shweder, R. A. (1996). True ethnography: The lore, the law and the lure. In R. Jessor, A. Colby, \& R. A. Shweder (Eds.), Ethnography and human development: Context and meaning in social enquiry (pp. 1552). Chicago: University of Chicago Press.

Smith, S. E. (2020). Is evolutionary psychology possible? Biological Theory, 15, 39-49. https://doi. org/10.1007/s13752-019-00336-4.

Srivastava, A. K., \& Misra, G. (2007). Rethinking intelligence: Conceptualizing human competence in cultural context. New Delhi: Concept Publications.

Stein, D. J., Phillips, K., Bolton, D., Fulford, K. W., \& Kendler, K. (2010). What is a mental/psychiatric disorder? From DSM IV - DSM V. Psychological Medicine, 40(11), 1759-1765.

Valsiner, J. (1997). Culture and the development of children's action: A theory of human development (2nd ed.). John Wiley \& Sons Inc..

Valsiner, J. (2007). Culture in minds and societies: Foundations of cultural psychology. New Delhi: Sage.

Valsiner, J. (2008). Introduction: The basics of trust: How culture matters. In B. Wagoner \& I. Markova (Eds.), Trust and distrust: Sociocultural perspectives (pp. ix-xvi). Charlotte, NC: Information Age.

Valsiner, J. (2014). The need for cultural psychology: Methodology in a new key. Culture and Psychology, 20(1), 3-20. https://doi.org/10.1177/1354067X13515941.

Valsiner, J. (2019). Hypergeneralisation by the human mind: The role of sign hierarchies. In First presented at 4th Hans Kilian Preis lecture Bochum, April 28, 2017. Giessen: Psychosozial Verlag.

Valsiner, J., \& Salvatore, S. (2012). How idiographic science could create its own terminology. In S. Salvatore, J. Valsiner, \& A. Gennaro (Eds.), Making sense of infinite uniqueness: The emerging system of idiographic science. Information Age: Charlotte, NC.

Van der Kolk, B. (2000). Post-traumatic stress disorder and the nature of trauma. Dialogues in Clinical Neuroscience, 2(1), 7-22.

Zagaria, A., Ando, A., \& Zennaro, A. (2020). Psychology: A giant with feet of clay. Integrative Psychological and Behavioral Science, 54, 521-562.

Publisher's Note Springer Nature remains neutral with regard to jurisdictional claims in published maps and institutional affiliations.

Nandita Chaudhary is a Consultant and collaborator for projects, programmes and publications on Child Development, Family Studies and Cultural Psychology with specific reference to Indian communities. She blogs at Masala Chai: Musings about little people https://masalachaimusings.com/. She taught at Lady Irwin College, University of Delhi for over three decades before seeking early retirement. She has been a Fulbright Scholar and received Senior Fellow grants from UGC and Indian Council for Social Science Research. She has published her work as journal articles, chapters in books, edited books as well as an independent publication Listening to Culture from Sage.

Sujata Sriram is a Professor at the School of Human Ecology, Tata Institute of Social Sciences, (TISS) Mumbai. She enjoys teaching and research. She is eternally curious, and enjoys trying to find out what makes people tick. Her areas of research interest are many - families, childcare and parenting; marriage and divorce; mental health and wellbeing; meaning making of identity, religion and spirituality. 